\title{
७MONÇÕES
}

\section{Instituições e organização da ajuda no processo de inclusão do ProSAVANA na agenda brasileira de cooperação internacional}

\author{
Institutions and aid organization at the ProSAVANA \\ insertion in the Brazilian agenda of \\ International Cooperation
}

\section{Instituciones y organización de la asistencia en el proceso de inclusión de ProSAVANA en la agenda brasileña de cooperación internacional}

\author{
Laís Caroline Kuss \\ Programa de Pós-Graduação em Ciência Política, Universidade Federal de \\ Pernambuco (UFPE) \\ Recife Pernambuco, Brasil. \\ E-mail: lais.kuss@ufpe.br \\ Orcid: 0000-0001-8919-8161
}

\begin{abstract}
Resumo: A cooperação triangular tem ganhado proeminência na ajuda internacional. Ao mesmo tempo, ao longo dos governos petistas, o Brasil buscou ser protagonista na Cooperação Internacional para o Desenvolvimento, contexto no qual o ProSAVANA, parceria triangular, ganhou destaque. Apesar disso, ainda foram pouco explorados os aspectos domésticos que podem ter contribuído para a adoção do programa. Assim, neste trabalho, o objetivo é observar de que maneira as instituições e a organização da ajuda podem ter contribuído para a adoção do ProSAVANA na agenda da cooperação internacional para o desenvolvimento do Brasil. Serão utilizados os fatores domésticos propostos por Lancaster (2007), para quem quatro forças domésticas (incluindo instituições e organização da ajuda) são relevantes para a alocação da ajuda. Na primeira seção será apresentada uma revisão da relevância das instituições e organização da ajuda, seguida da introdução ao ProSAVANA e de uma seção dedicada às instituições e organização da ajuda brasileiros na adoção do programa na agenda. Como resultados centrais, aponta-se o papel da ABC e da EMBRAPA no contexto do momentum da CID agrícola do Brasil. Ademais, observou-se uma coordenação pacífica entre as burocracias envolvidas, apesar da necessidade de avanço nessa coordenação, bem como da consolidação dos marcos legais e institucionais da CID no país.
\end{abstract}

Palavras-chave: Cooperação triangular; ProSAVANA; Instituições. 
Abstract: Triangular cooperation has gained prominence in international aid. At the same time, throughout PT governments, Brazil sought to be a protagonist in International Development Cooperation, a context in which ProSAVANA, a triangular partnership, gained prominence. Despite this, the domestic aspects that may have contributed to the adoption of the program have been underexplored. Thus, in this work, the objective is to observe how the institutions and the aid organization may have contributed to the adoption of ProSAVANA in the international cooperation agenda for the development of Brazil. The domestic factors proposed by Lancaster (2007) will be used, for whom four domestic forces (including aid institutions and organization) are relevant for aid allocation. In the first section, a review of the relevance of the institutions and organization of aid will be presented, followed by the introduction to ProSAVANA and a section dedicated to the institutions and organization of Brazilian aid in the adoption of the program on the agenda. As central results, the role of $A B C$ and EMBRAPA in the context of the momentum of the agricultural IDC in Brazil is pointed out. Furthermore, there was peaceful coordination between the bureaucracies involved, despite the need for progress in this coordination, as well as the consolidation of the legal and institutional frameworks of the ICD in the country.

Keywords: Triangular cooperation; ProSAVANA; Institutions.

Resumen: La cooperación triangular ha ganado protagonismo en la ayuda internacional. Al mismo tiempo, a lo largo de los gobiernos del PT, Brasil buscó ser protagonista de la Cooperación Internacional para el Desarrollo, contexto en el que ProSAVANA, una alianza triangular, ganó protagonismo. A pesar de esto, los aspectos domésticos que pueden haber contribuido a la adopción del programa han sido poco explorados. Así, en este trabajo, el objetivo es observar cómo las instituciones y la organización de la asistencia pueden haber contribuido a la adopción de ProSAVANA en la agenda de cooperación internacional para el desarrollo de Brasil. Se utilizarán los factores internos propuestos por Lancaster (2007), para los cuales cuatro fuerzas internas (incluidas las instituciones y la organización de la asistencia) son relevantes para la asignación de la ayuda. La primera sección presentará una revisión de la relevancia de las instituciones y organizaciones de asistencia, seguida de la introducción a ProSAVANA y una sección dedicada a las instituciones y organizaciones de ayuda brasileñas en la adopción del programa en la agenda. Como resultados centrales, se señala el papel de ABC y EMBRAPA en el contexto del impulso de la CID agrícola en Brasil. Además, hubo una coordinación pacífica entre las burocracias involucradas, a pesar de la necesidad de avanzar en esta coordinación, así como la consolidación de los marcos legales e institucionales de la CID en el país.

Palavras-chave: Cooperación Triangular; ProSAVANA; Instituciones.

Recebido em 21/02/2020

Aceito em $11 / 04 / 2020$. 


\section{CONSIDERAÇÕES INICIAIS}

O Programa de Cooperação Triangular para o Desenvolvimento da Agricultura na Savana tropical em Moçambique (ProSAVANA) tem como parceiros Brasil, Japão e Moçambique e foi concebido com o objetivo de desenvolver a agricultura na região Norte de Moçambique. Ele foi incluído na agenda da cooperação entre os três países em 2009 e teve sua implementação iniciada em 2011. Essa inclusão foi possibilitada pela abertura de uma "janela de oportunidade" para temas relacionados à garantia da segurança alimentar e para programas de cooperação triangular, em nível de contexto internacional/externo. Porém, de acordo com Lancaster (2007), para compreender o volume e alocação da ajuda internacional é também importante considerar aspectos da política doméstica dos países doadores.

No contexto da política doméstica, a autora preconiza a análise de quatro forças: ideias, interesses, instituições e organização da ajuda. Três desses elementos não são novos para as áreas das Relações Internacionais e da Ciência Política, em especial para os subcampos da Análise de Política Externa (APE) e da Análise de Políticas Públicas (APP), a análise dos interesses, ideias e instituições, chamados os Três l's. Portanto, a presente pesquisa caracteriza-se como um estudo de caso de caráter exploratório, por meio da qual busca-se contribuir com mais um caminho para a análise da Cooperação Internacional para o Desenvolvimento (CID), através da análise de fatores elencados por Lancaster (2007).

Essa escolha de análise do contexto doméstico brasileiro de adoção do ProSAVANA na agenda da cooperação foi realizada pelo reconhecimento de que outros autores também consideram interesses, instituições e ideias, como fatores importantes para compreender as políticas domésticas e a política externa. Observar esses aspectos permite atentar para a pluralidade das possíveis dimensões de análise e causas da ação pública. Assim, em busca de uma abordagem multicausal, diversos autores defendem a combinação dos Três I's para uma melhor compreensão das políticas.

Nesse contexto, foram escolhidas instituições e organização da ajuda como foco de análise devido às limitações de escopo e espaço de um artigo. O terreno das ideias constitui- 
se como mais complexo, dadas as questões de intangibilidade, portanto merecem um estudo próprio.

Assim, aqui o objetivo é observar a contribuição das instituições e da organização da ajuda, no contexto brasileiro, e de que maneira podem ter auxiliado como pano de fundo para a inclusão do ProSAVANA na agenda da cooperação triangular (CTr) brasileira, processo que aconteceu no ano de 2009. Esse marco delimita também o recorte temporal da pesquisa, que é o contexto de instituições e organização da ajuda do segundo governo Lula (2007-2010).

Para cumprir com o objetivo, a primeira seção resgata a relevância das instituições e da organização da ajuda para as decisões políticas, com destaque para o que aponta Lancaster (2007). Já a segunda seção é dedicada à apresentação do ProSAVANA, objeto deste estudo. Por fim, serão abordadas na terceira seção as forças domésticas escolhidas: instituições e organização da ajuda, com foco em sua contribuição para a adoção do ProSAVANA na agenda brasileira de cooperação.

Cabe ainda ressaltar que aqui os conceitos de Ajuda Internacional e Cooperação Internacional para o Desenvolvimento (CID) serão utilizados de maneira intercambiável. No entanto, na literatura, as instituições são uma categoria mais ampla, que abarca a Ajuda, mais utilizada para descrever a CID dos países doadores tradicionais e a Cooperação Sul-Sul para o Desenvolvimento, categoria utilizada para a CID dos chamados doadores emergentes, tal como Brasil, China, entre outros.

\section{Contexto doméstico como ferramenta de análise: os fatores de Carol Lancaster}

Em busca de uma abordagem multicausal, autores como Heclo (1994) e Hall (1993) defendem a combinação dos Três I's (interesses, instituições e ideias) para uma melhor compreensão das políticas. Desse modo, Lancaster (2007) está alinhada com esse tipo de abordagem, a qual aplica para o estudo da Ajuda Internacional.

O estudo dos interesses, das instituições e das ideias, como fatores que contribuem para as decisões dos governos, constitui o que é chamado de abordagem dos Três I's, que, 
apesar da denominação, não é um modelo integrado de análise. Algumas dessas perspectivas indicam a proeminência de um ou dois desses fatores, mas a maioria reconhece a relevância dos três. Os três I's são próprios da Ciência Política, especialmente voltados à análise de políticas públicas, mas encontram caminhos também nas RI e na Política Comparada.

Dentre os autores que reconhecem o papel da combinação entre os Três I's, Heclo (1994) aponta que o entendimento avança mais quando se concentra na interação entre interesses, instituições e ideias, que se influenciam reciprocamente. Assim, entender a reciprocidade é mais relevante do que compreender o que predomina. Segundo o autor, “interesses falam às instituições o que fazer; instituições falam às ideias como sobreviver; ideias falam aos interesses o que significar" (HECLO, 1994, p. 383). ${ }^{1}$ Com ênfase no papel das ideias e das instituições, Blyth (2003) afirma que o contexto da ação política é composto por locus institucionais e ideológicos que se combinam. Diferentemente, para Hall (1993), o locus de combinação das ideias e dos interesses são as instituições. Desse modo, cada autor dá maior relevo a determinados fatores.

Em termos de política externa, o Neoinstitucionalismo parece ocupar mais terreno nas RI, como observado pelo destaque que ganha o trabalho de Milner (1997). Nesse estudo, a fim de entender por que os Estados cooperam, a autora apresenta três variáveis-chave: as preferências dos atores domésticos, as instituições de compartilhamento de poder e as informações decisivas.

Além dessas abordagens, tem-se então Lancaster (2007), que transpõe os Três I's para o estudo da ajuda internacional. A principal questão que a autora procura responder em seu livro é: quais são os propósitos da ajuda e por que esses propósitos são escolhidos e não outros? ${ }^{2}$ Para tanto, a autora afirma ser essencial compreender:

As ideias amplamente compartilhadas e as normas que moldam a prestação de ajuda, as instituições políticas nas quais as decisões da ajuda são tomadas, os interesses que competem por influência sobre os propósitos da ajuda, e a

\footnotetext{
${ }^{1}$ Tradução livre do original: "interests tell institutions what to do; institutions tell ideas how to survive; ideas tell interests what to mean".

${ }^{2}$ Segundo ela, a ajuda externa possui múltiplos propósitos, porém, nem sempre a razão expressa reflete suas reais motivações. Dentre todos os propósitos, a ajuda possui quatro objetivos principais: desenvolvimento, alívio humanitário, diplomacia e comércio. Porém, esses propósitos estão sempre combinados, em um "mix de propósitos", embora por vezes um deles seja predominante.
} 
organização dos governos para gerenciar sua ajuda ${ }^{3}$ (LANCASTER, 2007, p. IX).

Carol Lancaster (1942-2014) foi uma pesquisadora e practioner estadunidense. Durante a sua carreira, atuou no Departamento de Estado dos Estados Unidos e na U.S. Agency for International Development (USAID). Como professora e pesquisadora, atuou na Georgetown University e no Center for Global Development. Portanto, constitui-se como uma referência na área de Ajuda Internacional, tendo escrito e editado diversos livros na área (CENTER FOR GLOBAL DEVELOPMENT, 2021).

Assim, a autora fornece um framework para a análise da construção da CID no ambiente doméstico. Como primeiro fator determinante na alocação da ajuda, são considerados pela autora os interesses, sejam eles públicos e privados, com foco nos grupos/instituições e não nos indivíduos, apesar de alguns serem citados especialmente. Os interesses são o fator mais dinâmico da política doméstica, na perspectiva de Lancaster (2007). De acordo com ela, há três tipos de motivações na ajuda internacional: propósitos comerciais, interesses públicos e grupos de afinidades com países, etnias e orientações religiosas específicas. Sua influência depende do acesso que os atores possuem ao processo decisório. Daí a importância de estudar as instituições e a organização da ajuda na estrutura decisória (LANCASTER, 2007).

Ao contrário dos interesses, as ideias demoraram mais para ganhar relevância nas análises políticas. Nesse sentido, a dificuldade em definir, mensurar e até mesmo observar a atuação das ideias nas decisões políticas surgem como desafios (CUNHA, 2009; FARIA, 2003). No entanto, as ideias são relevantes inclusive para compreender os interesses. Nessa relação, as ideias contribuem com a formação dos interesses ao dar um contexto de maior ou menor legitimidade a determinados interesses e preferências (HALL, 1993; CUNHA, 2009).

Para Carol Lancaster (2007) interessa analisar as visões de mundo, as normas e as crenças causais. Assim, as visões de mundo constituem-se como os valores amplamente compartilhados, baseados na cultura, religião, ideologia e fruto também da história. Por sua

\footnotetext{
${ }^{3}$ Tradução livre do original: "the widely shared ideas and norms shaping aid- giving, the political institutions in which aid decisions are made, the interests competing for influence over aid's purposes, and the organization of governments to manage their aid".
} 
vez, as visões de mundo dão origem a normas e crenças causais que, para Lancaster, são definidas, respectivamente, como as expectativas coletivas de comportamento e a percepção sobre o que é efetivo para determinado resultado.

Por fim, partimos para as forças que são aqui aplicadas ao caso do ProSAVANA: as instituições e a organização da ajuda. São as instituições que filtram e dão melhores oportunidades ou constrangem determinados interesses e ideias. Ao fazer isso, as instituições ajudam a moldar as preferências (KAELBERER, 2002) e estruturam as interações entre os atores (MILNER, 1997).

Nas últimas décadas, a rápida difusão de enfoques institucionalistas na Ciência Política (que também atingiu as RI), foi propiciada pelo surgimento do Neoinstitucionalismo, abordagem dedicada ao papel das instituições nas decisões políticas (TAPIA, GOMES, 2008). Nesse escopo, para Keohane e Milner (1996), as instituições determinam a margem de manobra dos governantes e cumprem três papéis principais: bloquear as alterações, congelar coalizões e políticas e orientar as estratégias de resposta dos líderes.

Em Goldstein e Keohane (1993), no estudo da institucionalização das ideias, o papel das instituições na política externa, inclui análise das: agências administrativas, leis, normas e procedimentos operacionais. Assim, é possível identificar como os atores participam do processo decisório e quais são seus mecanismos de participação (CORTINHAS, 2006; ARAGÃO, 2011).

De acordo com Kaelberer (2002), o insight básico da análise institucional é que as instituições não são politicamente neutras, mas carregam interesses políticos. Desse modo, são um meio de poder, pois são as instituições políticas domésticas que determinam como o controle das decisões de política externa é distribuído (MILNER, 1997), sendo as desigualdades e diferenças no acesso ao sistema político-institucional marcas de seu processo decisório (MILANI, 2015). Nesse sentido, quanto maior o controle do processo, maior a capacidade dos atores de implementar suas preferências. Para tanto, segundo Milner (1997), são quatro os recursos de poder para atores dominantes: poder de agenda, capacidade de emendar propostas, ratificação e veto de propostas, proposição de referendos.

A partir de tais recursos, observa-se que, sendo os atores governamentais aqueles que 
possuem destaque no controle do processo, possuem também maior poder. Desse modo, pode-se esperar que graus distintos de permeabilidade e capacidade estatal gerem políticas diferentes, sendo que quanto maior a autonomia estatal, maior a importância das ideias e interesses dos atores governamentais (CUNHA, 2009).

Esses autores estão em sintonia com Lancaster (2007, p.6), para quem as instituições "determinam quem tem acesso as decisões, quem decide, quem veta; e criam incentivos para a ação por parte de interesses organizados" ${ }^{4}$. Para a autora, fazem parte desse fator, a estrutura de governo e as regras eleitorais. Aqui também são incluídos os papeis que desempenham os governos locais e entidades semipúblicas, tais como comitês de aconselhamento e ONG's apoiadas pelo Estado. Em relação às regras eleitorais, elas afetam indiretamente a agenda, porque influem nas coalizões partidárias, dando chance para que partidos menores insiram seus temas na agenda.

“A maioria das análises dos fatores afetando políticas públicas param depois de considerar ideias, instituições e interesses ou agrupam a organização do governo na categoria mais ampla de "instituições'” (LANCASTER, 2007, p.22). Por outro lado, para Lancaster, isso é um erro no caso da ajuda, porque sua organização afeta a maneira que a ajuda tem voz dentro de um governo e também a colaboração das agências do governo com outros grupos. Assim, dá especial foco na organização da ajuda.

Na perspectiva da autora, a organização da ajuda afeta o peso que a mesma tem dentro dos governos e a extensão da colaboração com grupos de fora do governo. Diz respeito à relação do órgão que promove a ajuda com o governo, as agências governamentais e não governamentais. Quanto mais elevada sua localização burocrática e mais unificada a agência que promove a ajuda, maior sua influência no governo. No sentido inverso, é a organização da ajuda que institucionaliza os interesses e propósitos do governo. Assim, agências governamentais constituem-se como importantes atores políticos.

Não foram encontrados outros trabalhos que tratassem dessa força como fator relevante para a ajuda internacional, nem mesmo algum fator relacionado que contribuísse

\footnotetext{
${ }^{4}$ Tradução livre do original: "They determine who has access to decisions, who decides, who vetoes; and they create incentives for action on the part of organized interests".
} 
com o processo decisório. Por isso, aqui utiliza-se apenas a definição de Lancaster (2007), contando com elementos da análise das instituições, porém aplicados à ajuda.

\section{ProSAVANA: "something that nobody knows" ?}

O ProSAVANA foi um programa, desenvolvido por Brasil, Japão e Moçambique, que emergiu no contexto da longa relação Brasil-Japão e da aproximação desses dois, no início do século XXI, com Moçambique. Em abril de 2007, no âmbito do Programa de Parceria Japão-Brasil (PPJB), marco da CTr entre Brasil e Japão, Celso Amorim, então ministro das Relações Exteriores do Brasil, e Sadako Ogata, então presidente da Agência de Cooperação Internacional do Japão (JICA), anunciaram o fortalecimento da CID conjunta para a África.

A partir disso, o primeiro marco da inclusão do programa na agenda da cooperação entre Brasil e Japão aconteceu em abril de 2009, quando o então vice-presidente sênior da JICA, Kenzo Oshima, assinou com o então diretor da ABC, Marco Farani, uma minuta comprometendo-se em desenvolver conjuntamente um programa de cooperação na Savana tropical africana. Nessa ocasião, foi apresentada ao Brasil a primeira proposta, estabelecendo a preferência pela aplicação do programa em Moçambique (ABC, JICA, MINAG, 2009).

Um mês após a visita de Oshima, uma missão do Ministério da Agricultura moçambicano (MINAG) veio ao Brasil conhecer o modelo de desenvolvimento agrícola do cerrado (ABC, JICA, MINAG, 2009). O modelo implementado no cerrado, a partir da década de 1970, fez parte do processo de modernização do campo que se iniciou no Brasil nas décadas de 1950 e 1960 (INOCÊNCIO, 2010, p.24). Um dos elementos centrais dessa modernização foi o Programa de Cooperação Nipo-Brasileira para o Desenvolvimento dos Cerrados (PRODECER), implementado por Japão e Brasil na década de 1970. Foi a partir dele que o país passou a ser visto como modelo para o desenvolvimento da agricultura e o programa como referência de

\footnotetext{
${ }^{5}$ O título da seção faz referência a entrevista com representante do ORAM, feita e citada por Natalia Fingermann em 2014, na qual o entrevistado refere-se aos mal-entendidos e informações desencontradas sobre o ProSAVANA.
} 
ajuda do Japão ao Brasil. Assim, mais tarde, o PRODECER serviu como base para a idealização do ProSAVANA (ABC, JICA, MINAG, 2009).

Na ocasião da missão do MINAG ao Brasil, foi encaminhada a primeira proposta de discussão envolvendo Moçambique. Em julho de 2009, Brasil e Japão concordaram em promover um programa de desenvolvimento agrícola nas savanas africanas, de maneira a utilizar o conhecimento adquirido no PRODECER (ABC, JICA, MINAG, 2009). Em setembro, Brasil e Japão organizaram uma missão conjunta a Moçambique e então assinaram o Memorando tripartite que deu origem ao programa (ABC, JICA, MINAG, 2009; FINGERMANN, 2014).

No ProSAVANA, assim como no PRODECER, Brasil, Japão e Moçambique adotam uma abordagem holística ao buscarem potencializar o setor agrícola como um todo. Sua proposta foi desenvolver a cadeia produtiva agrícola completa, de maneira a tornar a produção moçambicana competitiva, sustentável e orientada para o mercado (PROSAVANA, 2015, sn).

Do ponto de vista da cooperação brasileira, o ProSAVANA está inserido no Programa EMBRAPA-ABC Moçambique, a partir do qual se iniciaram o mapeamento e o zoneamento geográfico da área-alvo, antes mesmo da entrada do ProSAVANA na agenda (BATISTELLA, BOLFE, 2010). O EMBRAPA-ABC Moçambique é um conjunto de projetos que envolvem a EMBRAPA (Empresa Brasileira de Pesquisa Agropecuária) e a transferência da tecnologia agrícola brasileira para Moçambique. No caso do Japão, o ProSAVANA é parte do Projeto de Estratégias de Desenvolvimento Econômico no Corredor de Nacala (PEDEC-Nacala), parceria estabelecida em 2011 entre a JICA, o Ministério de Economia e Finanças de Moçambique (MEF) e o escritório da Zona Econômica Especial de Nacala. Seu objetivo é elaborar estratégias integradas de desenvolvimento e estabelecer projetos prioritários para Moçambique até 2035.

A área-alvo do projeto é o Corredor de Nacala, abrangendo quatro províncias: Nampula, Cabo Delgado, Niassa e Tete, além de sete distritos ao norte da província de Zambézia (JICA, 2016; MEF, JICA, 2015; JICA, 2017). Estima-se que haja, na região, 4 milhões de hectares de terra arável não florestal, dos quais apenas 930 mil são cultivados, predominantemente (99\%) em pequenas propriedades, nas quais a maioria da população 
depende da agricultura (CLEMENTS, 2015).

O ProSAVANA foi dividido em duas fases. A primeira foi chamada de "Preparação do Programa", constituída de quatro componentes: estudo preliminar, melhora das capacidades físicas e institucionais em pesquisa, difusão do conhecimento agrícola e, por fim, desenvolvimento do Plano Diretor e de novos modelos de desenvolvimento (MINAG et al., 2013; ABC, JICA, [2010]). Já a segunda constitui-se como a fase de "Execução", na qual os modelos criados serão expandidos (ABC, JICA, MINAG, 2009; SCHLESINGER, 2013).

O gerenciamento do ProSAVANA seria feito por um Grupo de Trabalho Tripartite, formado pelos representantes dos três países parceiros: ABC, JICA e MINAG. Estes são também os pontos focais dos grupos de trabalho de cada um dos países, "encarregados de obter consenso entre os órgãos envolvidos e de gerenciar o progresso de cada atividade [desenvolvida no âmbito do programa]" (ABC, JICA, MINAG, 2009).

O Instituto de Investigação Agrária de Moçambique (IIAM) e a EMBRAPA, órgãos públicos, seriam responsáveis pela execução do componente de pesquisa do programa. Os demais, que envolvem zoneamento, crédito e extensão rural, deveriam ser implementados por think tanks, empresas de consultoria agrícola de extensão e ministérios federais. Isso mostra a variedade de atores envolvidos na iniciativa. Nesse sentido, uma das características do ProSAVANA que, segundo Sakaguchi (2012), não é comum na cooperação triangular, são as parcerias entre o setor público e o setor privado, desde o início do programa. Ainda de acordo com o autor, seria impossível atingir a escala esperada sem essa particularidade. Contudo, há uma tendência na CID para o aumento no número de parceiros e para o estabelecimento de parcerias público-privadas, que têm sido incentivadas dentro do sistema da ajuda em documentos como o Terceiro Arranjo do PNUD para a CSS (2005) ${ }^{6}$.

Vários elementos do programa foram duramente criticados. As preocupações centrais foram resumidas por Clements (2015) nos seguintes pontos: falta de transparência; falta de diálogo e acesso à informação; adoção de um modelo que gerará destruição de sistemas ecológicos; geração de insegurança alimentar e exclusão social; e causa de degradação da

${ }^{6}$ Disponível em: https://www.unsouthsouth.org/library/policy-documents/. 
soberania nacional e de direitos civis dos moçambicanos. Por sua vez, o trabalho de Schlesinger (2013) traz um resumo das principais preocupações dos camponeses, expressas em um documento da UNAC, em 2012: 1. expropriação de terras e surgimento de camponeses sem-terra; 2 . danos ambientais e desequilíbrio ecológico; 3. êxodo rural e maior insegurança alimentar.

Para além das críticas ao modelo do ProSAVANA e à falta de transparência, Fingermann (2014) atenta para os desafios relacionados à CID brasileira e à CTr, tais como as fragilidades administrativas e econômicas da $A B C$ e os conflitos de paradigmas entre os "doadores emergentes" e os "doadores tradicionais". Dessa maneira, como primeiro ponto, Fingermann (2014) sublinha a falta de integração entre projetos de cooperação levados a cabo em Moçambique, o que não contribui para o desenvolvimento do país. Outros aspectos apontados são a falta de coordenação entre Japão e Brasil, a baixa institucionalização da cooperação no Brasil e a falta de preparo do MRE e da $A B C$ para a implementação do programa.

\section{Instituições e Organização da Ajuda e a adoção do ProSAVANA na agenda}

Desde a Constituição de 1988 o Brasil é uma república federativa, presidencialista, multipartidária, em um regime democrático de representação proporcional. Dentro dessa combinação, Abranches (1988) caracteriza o país como um "presidencialismo de coalizão", no qual o Executivo depende de uma grande coalizão de partidos para governar. Isso ocorre devido, sobretudo, à heterogeneidade e diversidade da sociedade brasileira. Essa denominação é corroborada por uma série de autores, incluindo Limongi (2006), que, ao mesmo tempo, afirma que nossa última constituição reforçou o poder institucional do presidente ${ }^{7}$. Assim, o poder de agenda no Brasil é do Executivo, que em geral logra aprovar

\footnotetext{
${ }^{7}$ Vale ressaltar que no período anterior ao Impeachment de Dilma Rousseff, recorte temporal ao qual se refere esta pesquisa, havia um consenso na Ciência Política de que o Brasil era, de fato, um presidencialismo de coalizão. Atualmente, essa característica do nosso sistema político está em discussão, pelas transformações em curso a partir de 2016. Outra ressalva está nas diferenças entre
} 
suas proposições, já que conta com apoio partidário. Nas relações exteriores do Brasil, o poder do Executivo parece ser ainda maior, como se verá a seguir.

Em nossa Constituição é estabelecido que a União possui a prerrogativa de manter relações com Estados estrangeiros e participar de organizações internacionais; declarar a guerra e celebrar a paz; assegurar a defesa nacional; permitir, nos casos previstos em lei complementar, que forças estrangeiras transitem pelo território nacional ou nele permaneçam temporariamente (CF, 1988, artigos 21 e 22), ou seja, de formular e promover relações internacionais. Dentro dessa esfera, é competência privativa do Presidente da República manter relações com Estados estrangeiros, acreditar seus representantes diplomáticos (art. 84, VII) e celebrar tratados, convenções e atos internacionais, sujeitos a referendo do Congresso Nacional (art. 84, VIII) (CF, 1988). Assim, denota-se que a competência das relações internacionais do Brasil está sob o Executivo Federal, com extensos poderes conferidos ao presidente.

Apesar disso, a partir da literatura, observa-se o papel central do Ministério de Relações Exteriores (MRE/Itamaraty) como aquele que formula e coloca em prática grande parte dos princípios e ações da política externa. Nesse sentido, Pinheiro (2009) afirma que a delegação ou omissão do presidente é requisito fundamental na definição de competências na formulação, condução e aplicação da PEB contemporânea. Dessa maneira, o Executivo delega a tarefa ao MRE.

No mesmo sentido, Figueira (2009), em seu estudo do processo decisório na PEB, aponta que as burocracias, tal como o MRE, são relevantes e influentes devido a sua capacitação técnica, especialização e continuidade. Assim, o Itamaraty aparece na literatura e de acordo com a diplomacia oficial como o guardião da PEB, porque detém a capacidade de coesão e coerência e a expertise nos temas relacionados a ela, dado historicamente. Portanto, o MRE coordena todo o processo decisório, em especial a definição da agenda, a formulação e a decisão em política externa (SILVA, SPÉCIE, VITALE, 2010).

Limongi e Abranches, pois enquanto o segundo vê no presidencialismo de coalizão um sistema instável, o primeiro ressalta o poder de agenda do presidente. 
Já a função do Congresso brasileiro é complementar. É amplo o debate na academia sobre o interesse e a influência (ou não influência) dos parlamentares brasileiros nas decisões de política externa ${ }^{8}$. Parece um consenso na literatura de que a influência direta do Congresso é pequena e dificultada pela previsão legal, já que a prerrogativa e o controle da agenda são do Executivo. A principal competência do Legislativo, em matéria de política externa, é a de aceitar ou rejeitar acordos internacionais (depois que já foram negociados). Tal capacidade encontra ainda uma barreira adicional, devido a quantidade de acordos que não passam pelo processo de aprovação legislativa (FIGUEIRA, 2009; DINIZ, RIBEIRO, 2010)

Quando um ato internacional necessita da aprovação do Congresso, passa primeiro pela Comissão de Relações Exteriores e Defesa Nacional (CREDN), da Câmara dos Deputados, que emite um decreto legislativo aprovando o ato. Após isso, ele passa pela Comissão de Constituição, Justiça e Cidadania e por comissões relacionadas ao tema (caso necessário), antes de ir ao plenário em votação única. Depois da Câmara, o ato passa pela mesma dinâmica no Senado até chegar à mesa do presidente, que ratifica e o publica no Diário Oficial da União. Contudo, a maioria dos atos internacionais do Brasil não passam por tal processo (FIGUEIRA, 2009).

Nesse sentido, os Acordos Executivos, aqueles que não precisam de aprovação congressual para entrar em vigor, ganham destaque no Brasil. Dos 1821 atos internacionais bilaterais celebrados entre 1988 e 2007, 1423 foram Acordos Executivos, ou seja, 78\% do total (FIGUEIRA, 2009). No caso dos acordos entre o Brasil e Moçambique, por exemplo, uma consulta às atas das reuniões da CREDN da Câmara dos Deputados brasileira, bem como a seus relatórios de atividades, mostra que, entre 2003 e 2010, apenas um acordo sobre consumo e tráfico ilícito de entorpecentes (um no domínio da defesa e outro sobre extradição), além da doação referente à instalação da fábrica de antirretrovirais e o memorando na área de biocombustíveis são mencionados ${ }^{9}$. Por outro lado, na

\footnotetext{
${ }^{8}$ Mais sobre a participação do Legislativo na PEB pode ser encontrado em: Diniz e Ribeiro (2008 e 2010), Anastasia, Mendonça e Almeida (2012), Diniz (2010).

${ }^{9}$ As pesquisas foram feitas no site da Comissão de Relações Exteriores e Defesa da Câmara dos Deputados, nas atas de todas as suas reuniões entre 01 de janeiro de 2003 e 31 de dezembro de 2010; e em todos os relatórios de atividades de 2003 a 2010.
} 
internacionalização de agências públicas, como a EMBRAPA, essenciais para a implementação da CID brasileira, o Legislativo cumpre papel importante, já que é o responsável por autorizar a abertura de escritórios/representações das mesmas no exterior.

Além do Legislativo, os partidos são considerados um dos elos centrais entre o governo e o povo (HEBLING, 2015). No período do ProSAVANA, havia reconhecimento da influência do PT na PEB, expressa nas ideias que permearam a mesma. Isso é resultado também da relação entre o presidente, seu partido e a política externa, em uma época em que a diplomacia presidencial ganhou destaque. Dessa maneira, a contribuição ativa do presidente Lula e de membros do partido na formulação e implementação da PEB, garantiram a influência do PT nessa seara (FIGUEIRA, 2009; ALMEIDA, 2012).

O MRE é o órgão encarregado das relações internacionais do Brasil, com exceção dos assuntos financeiros (ALMEIDA, 2012). De acordo com o Artigo 1ㅇ de seu regimento (Decreto $n^{\circ}$ 5.979/2006), estão sob sua responsabilidade a política internacional; as relações diplomáticas e consulares; a participação nas negociações comerciais, econômicas, técnicas e culturais com governos e entidades estrangeiras; os programas de cooperação internacional e promoção comercial; o apoio a delegações, comitivas e a representação do Brasil em agências e organismos internacionais e multilaterais (SILVA, SPÉCIE, VITALE, 2010).

O processo de construção da instituição dotou-a de grande força, o que explica a ideia de coerência e continuidade do Itamaraty (DOVAL, 2013). Foi essa construção que gerou uma estrutura complexa, profissional e coesa, na qual o controle garante a continuidade e a credibilidade de suas ações e princípios centrais (PINHEIRO, 2009; FIGUEIRA, 2009; ALMEIDA, 2012).

Desse modo, estabeleceu-se um processo decisório altamente hierarquizado, formalizado, burocratizado e com número restrito de atores-chave. As instruções que dizem respeito a temas novos oudecisões que comprometem posições do país são tomadas pelo ministro ou pelo próprio presidente e as unidades da base possuem pouca autonomia decisória. Quanto à estrutura, ela foi mantida homogênea ao longo do tempo, sendo o Itamaraty composto pelo gabinete do ministro, secretarias-gerais (superiores aos departamentos) e unidades setoriais (comunicação, cerimonial, áreas geográficas e temáticas) 
(FIGUEIRA, 2009; ALMEIDA, 2012). Contudo, a partir do processo de redemocratização do Brasil e fim da Guerra Fria, tem-se falado na literatura sobre um processo de horizontalização e pluralização da PEB (SILVA, SPÉCIE, VITALE, 2010).

De acordo com Spécie, Silva e Vitale (2010), uma análise dos regimentos e outros instrumentos legais dos órgãos executivos federais do Brasil demonstram uma tendência geral à horizontalização na PEB no início do século XXI. Ou seja, uma crescente presença de outros ministérios na tomada de decisão em política externa. Esse processo inclui descentralização de competências entre várias burocracias, o que não necessariamente implica em maior participação social, porém tem sido relacionada também a ela (FRANÇA, SANCHEZ, 2009).

Com relação à horizontalização específica da política externa, o contexto externo pósGuerra Fria, o contexto doméstico de abertura econômica e política e a incorporação de temas transversais à agenda contribuíram para esse fenômeno. A horizontalização faz parte de um processo amplo de pluralização de atores com atuação internacional e participação na política externa. Esse movimento envolveu outros poderes, entes subnacionais, agências do próprio Executivo federal e atores não estatais, o que gerou maior abertura de diálogo entre Estado e sociedade (LIMA, 2005; FIGUEIRA, 2009; SILVA, SPÉCIE, VITALE, 2010).

Esse processo adquiriu maior força durante os governos FHC e Lula. No mesmo período, houve a criação de espaços/canais de diálogo com outros órgãos da administração pública e o aumento de interação entre diversos atores, com a construção de redes de políticas e mudanças nos mecanismos de interlocução (SILVA, SPÉCIE, VITALE, 2010, ALBUQUERQUE, 2013). No entanto, esses dois fenômenos encontram com forças contrárias: o ponto de partida, que foi a situação quase monopolística, e o insulamento do MRE (DOVAL, 2013); o fortalecimento da diplomacia presidencial (CASON, POWER, 2009) e a manutenção da estrutura decisória interna do Itamaraty (FIGUEIRA, 2009), gerando uma dicotomia entre centralização e descentralização (SILVA, SPÉCIE, VITALE, 2010).

Durante o governo Lula ocorreram transformações importantes no organograma da Secretaria de Estado das Relações Exteriores. Somado a isso, a mudança de ênfase para a solidariedade e o engajamento com os países do Sul geraram consequências no estilo e na substância da tomada de decisão na PEB. Na perspectiva de Almeida (2012), isso levou a que 
as decisões passassem a ser tomadas por uma grande base do alto-escalão. Esse movimento teria gerado redução do papel da diplomacia profissional e proeminência da presidência, sobretudo do assessor Marco Aurélio Garcia, na visão do autor.

Houve também a expansão da especialização geográfica e temática do MRE, que levou ao crescimento e redefinição dos quadros da instituição e à alteração do perfil dos concursos. Para Silva, Spécie e Vitale (2010), essas mudanças foram parte da tentativa do MRE de "recentralizar" seu poder. Como exemplos, podem ser citados a participação do MRE em comissões mistas interministeriais e a própria cessão de diplomatas a outros ministérios. Nesse contexto, a pluralização foi chamada por Pinheiro (2009) de "verticalização controlada" e mesmo o processo de horizontalização é chamado por autores, como Albuquerque (2013), de "horizontalização controlada", porque os canais são abertos pelo MRE, que assim pode imprimir certa seletividade.

Quanto à cooperação interburocrática, surgem também desafios como a sua estrutura regimental, que nem sempre corresponde à implementação prática, já que as assessorias internacionais das mesmas, por vezes, são estabelecidas por portarias. Outro desafio são as contradições entre o escopo normativo referente aos níveis organizacionais, ou seja, há contradição entre o que se estabelece como competência

do órgão superior e dos executivos. Um exemplo disso seria: o regimento do órgão superior (ministério) prevê atuação em implementação e o regimento do órgão executivo (secretaria) prevê uma competência em formulação. Há ainda poucas previsões de articulação entre ministérios, secretarias e o MRE, sobreposição de competências e falta de critérios prévios e claros de participação de outros atores. Esse último ponto corrobora com a tese da "verticalização controlada", já que abre espaço para utilização de critérios conforme os interesses do Itamaraty (SILVA, SPÉCIE, VITALE, 2010). Portanto, há barreiras legais, técnicas e políticas (no ambiente externo ou na própria burocracia) para uma efetiva cooperação interburocrática com as lideranças das burocracias ocupando papel essencial em sua coordenação (FARIA, NOGUEIRA, LOPES, 2012).

A ampliação de espaços de atuação de outros atores (não só das burocracias) é especialmente destacada na CID. Segundo Albuquerque (2013), há uma relação entre a 
internacionalização de políticas públicas e a porosidade decisória do MRE, já que outros atores da burocracia federal atuam na implementação dessas políticas.

No ano de 1973, o Brasil se inseriu no sistema de ajuda como prestador de CID, com base na sua experiência como receptor e devido à intensificação da ação diplomática na América Latina e na África. Em 1987 foi criada a Agência Brasileira de Cooperação ( $A B C)$, responsável pela coordenação da cooperação técnica internacional do Brasil, como parte da Fundação Alexandre de Gusmão (FUNAG) e, portanto, vinculada ao MRE. Em 2001, a ABC deixou de fazer parte da FUNAG e foi incorporada diretamente à estrutura do MRE, mas somente em 2002 a agência começou a financiar projetos com orçamento próprio (PUENTE, 2010). $O$ artigo 30 do Decreto $n^{\circ} 5.979 / 2006$ apresenta as competências que a $A B C$ possuía até 2010, ano limite do período aqui estudado:

(...) coordenar, negociar, aprovar, acompanhar e avaliar, em âmbito nacional, a cooperação para o desenvolvimento em todas as áreas do conhecimento, recebida de outros países e organismos internacionais e aquela entre o Brasil e países em desenvolvimento (Decreto $\left.\mathrm{n}^{\circ} 5.979 / 2006\right)^{91}$.

Em 2006, a ABC passou a estar subordinada à Subsecretaria-Geral de Cooperação e Promoção Comercial (Decreto $n^{\circ}$ 5.979/2006) (BRASIL, 2006), uma das áreas do MRE com maior porosidade em relação a outros atores no processo de pluralização da PEB (FIGUEIRA, 2009, p.143). Durante o governo Lula a Agência ganhou força, tendo o número de países beneficiados aumentando de 21 para 58 e o número de atividades novas por ano indo de 30 , em 2004, a 472, em 2010 (ABC, 2017; BERTANI, PAUTASSO, 2014).

O aumento, porém, não refletiu em mudanças institucionais e legais (LEITE et al., 2014). Consequentemente, a multiplicação rápida de projetos em um curto período de tempo levou a uma sobrecarga da capacidade humana e financeira do Brasil, além da superposição de instituições. Nesse sentido, Alves (2013) critica a falta de uma legislação específica que permita a definição de objetivos, escopo, mecanismos, competências e processos. Ademais, a lei no Brasil proíbe alocação de recursos em outros países para propósitos de cooperação/benefício dos mesmos. Devido a isso, para colocar em prática as iniciativas são utilizados arranjos com a participação do PNUD (CABRAL, WEINSTOCK,2010 apud CHICHAVA, 
DURÁN, 2016). A falta de base legal e de mecanismos veio acompanhada de outras críticas em direção às demandas de inclusão da sociedade civil, à característica questionável da apropriação pelos países receptores, à falta de transparência e aos problemas de coordenação intra e intersetorial na CID brasileira (ALVES, 2013; LEITE et al, 2014).

Não há uma estratégia única e coerente, publicamente formulada, da cooperação prestada pelo Brasil. Assim, aqueles que a formulam possuem como base os princípios de política externa e os programas e projetos anteriores, contando com forte papel das missões do governo. Esse é um dos fatores para a existência de grande dispersão no sistema de CID do Brasil. A base legal das iniciativas são acordos básicos bilaterais, ajustes complementares e protocolos sob um acordo-quadro geral. Portanto, no período de adoção do ProSAVANA havia um processo de profissionalização da $A B C$, porém com processos de planejamento, monitoramento e avaliação ainda fracos (ALVES, 2013; LEITE et al, 2014; IPEA, ABC, 2010).

A assistência da $A B C$ é baseada no desenvolvimento de habilidades, no fortalecimento da capacidade institucional e no compartilhamento de boas práticas, partindo da cooperação técnica (IPEA, 2010; ALVES, 2013). O financiamento de projetos pode acontecer via ABC, governo federal, PNUD, fontes multilaterais ou, no caso de CTr, países desenvolvidos (ALBUQUERQUE, 2013). Desse modo, o impacto das iniciativas coordenadas pela $A B C$ vai além de seu orçamento, já que há recursos humanos e financeiros vindos de outros ministérios e agências de implementação dos projetos (ALVES, 2013). No caso dos recursos vindos de parceiros implementadores, há necessidade de coordenação desde o processo de formulação dos projetos. Apenas em 2010, por exemplo, a cooperação técnica do Brasil foi executada com recursos orçamentários de 44 instituições da administração pública federal (IPEA, ABC, 2010).

Segundo Leite et al (2014), alguns fatores impedem o MRE de exercer maior liderança na cooperação, tais como o aumento do papel de outros agentes e o princípio da ação por demanda. Além disso, a $A B C$ possui suas próprias diretrizes, que incluíam, pelo menos até 2010, prioridade à programas e projetos com ciclos completos (que permitam maior alcance de resultados); projetos que estejam inseridos nas prioridades de desenvolvimento dos países parceiros receptores; preferência para iniciativas com potencial para multiplicação e sustentabilidade; e busca de uma definição clara da contrapartida do parceiro (não 
necessariamente financeira). Ainda segundo Puente (2010, p.122), não se pode subestimar a importância da oferta nesse processo, com relevância das entidades nacionais cooperantes, que "em tese poderia facilitar alguma tendência a indução de demandas".

O processo de CID prestada pelo Brasil inicia-se com as demandas de países em desenvolvimento, que são recebidas pela $A B C$ ou por delegações no exterior. Depois de avaliar as demandas, a Agência chama os órgãos necessários para sua execução/implementação e os termos dos projetos devem, então, ser negociados e aprovados por todos os parceiros (ALBUQUERQUE, 2013). Assim, a necessidade da

$A B C$ em contar com agências implementadoras nas iniciativas de CID contribui para que tais órgãos/instituições possuam poder de influenciar os projetos. Na implementação, outros atores podem projetar expectativas, objetivos institucionais e interesses e, eventualmente, impactar as políticas do governo (GONÇALVES 2011 apud MESQUITA, 2014).

Os principais parceiros do Brasil na implementação da CID são agências públicas, dentre as quais se destacam a FIOCRUZ e a EMBRAPA. Segundo o Ipea e a ABC (2010), ao todo mais de 170 órgãos do governo federal compõem o sistema de CID do país. Na perspectiva de Leite et al (2014), mesmo com a maior abertura relativa à participação de outros atores ao longo do governo Lula, não há muitos espaços permanentes de discussão sobre a CID, caracterizando o engajamento do governo com o setor privado e a sociedade civil como limitado ou ad hoc.

Quanto a participação da sociedade civil, não há estratégia de participação na formulação dos projetos. As iniciativas que contam com a participação de atores dessa seara respondem à mobilização da própria sociedade civil ou quando há interesse do governo em sua agenda para a sociedade civil ou política externa (LEITE et al., 2014). Desse modo, a CID também parece sofrer uma espécie de verticalização e horizontalização controladas.

Já a coordenação do MRE com os demais ministérios tende a ser pacífica e funcional. Há reconhecimento da autoridade do MRE na formulação da política de cooperação, o que não implica necessariamente uma hierarquia funcional, porém também não há uma relação completamente horizontal. Por outro lado, não há rivalização ou contestação, que poderiam acentuar a característica de hierarquia da relação (ALBUQUERQUE, 2013). 
Na perspectiva de Albuquerque (2013), a coordenação entre ministérios é mais fácil quando há objetivos convergentes. Como no Brasil os ministérios são controlados por ministros indicados pelo presidente, há uma tendência à convergência. Ademais, as burocracias desejam manter seu poder e orçamento e ganhar prestígio com o presidente. Portanto, em geral não convém rivalizar umas com as outras, o que vale também para a CID.

O Ministério da Agricultura, Pecuária e Abastecimento (MAPA), junto com o Ministério do Desenvolvimento Agrícola (MDA), foi uma das burocracias que ganhou espaço durante o governo Lula, como consequência da internacionalização das políticas de combate à fome (aqui incluindo o ProSAVANA) (ALBUQUERQUE, 2013). Além disso, o ministério reforçou sua atuação internacional a fim de contribuir com a internacionalização do setor agrícola, ao dar maior visibilidade e eliminar barreiras aos produtos brasileiros do setor.

O MAPA atua na negociação e implementação de acordos bilaterais, regionais e multilaterais do setor agrícola, por meio de sua Secretaria de Relações Internacionais do Agronegócio (SRI), que age visando fortalecer a imagem do Brasil como produtor de alimentos seguros e de qualidade (EMBRAPA, 2009). As mudanças institucionais no MAPA entre a década de 1990 e o governo Lula criaram uma nova dinâmica na relação entre o Ministério e o MRE, conferindo participação mais institucionalizada do primeiro na formulação da política externa agrícola (MACHADO, 2009). A instituição vinculada ao MAPA que interessa ao presente trabalho é a EMBRAPA.

A EMBRAPA foi criada em 1973 com a missão de “(...) viabilizar soluções para o desenvolvimento sustentável do espaço rural, com foco no agronegócio, por meio da geração, adaptação e transferência de conhecimentos e tecnologias, em benefício dos diversos segmentos da sociedade brasileira" (EMBRAPA, 2009, p.34). No período da assinatura do ProSAVANA, era a Assessoria de Relações Internacionais (ARI) da instituição que articulava, programava e geria as atividades internacionais da EMBRAPA. Nesse âmbito, a EMBRAPA possui mandato próprio para atuar internacionalmente e também uma política própria de cooperação em Ciência e Tecnologia. As bases da ARI eram as diretrizes da EMBRAPA e do MAPA, bem como a adequação de interesses do agronegócio às tendências mundiais. Além disso, seu objetivo era prospectar recursos financeiros para pesquisa, transferência ou 
absorção de conhecimentos do exterior (EMBRAPA, 2009, p.34). Posteriormente, a ARI foi transformada na Secretaria de Relações Internacionais da EMBRAPA, com regimento aprovado em 2014 (EMBRAPA, 2014).

A cooperação internacional faz parte da história da EMBRAPA, com destaque para seu papel na cooperação do Brasil com a JICA. Dessa maneira, a EMBRAPA tem sido o ator mais presente na PEB, excluindo o MRE, e foi um ator ativo na implementação de cooperação em agricultura entre 2003 e 2010 (ALBUQUERQUE, 2013; BARBOSA, 2011 apud LEITE et al., 2014). Em 2010 por exemplo, a EMBRAPA foi responsável por uma verba de $\mathrm{R} \$ 1.481 .688$ de gastos em cooperação internacional (IPEA, ABC, 2010). Nesse período, a crescente participação internacional da Empresa foi impulsionada pela globalização, pela projeção dos interesses do Brasil no exterior e pelo reconhecimento de sua expertise em agricultura tropical (EMBRAPA, 2009).

A parceria EMBRAPA-ABC para adaptação de tecnologias brasileiras no exterior possui abordagem de longo prazo, com foco em projetos estruturantes (BERTANI, PAUTASSO, 2014; ALBUQUERQUE, 2013). Quanto aos atos internacionais que a EMBRAPA pode estabelecer, estes são denominados atos institucionais, dos quais fazem parte as cartas de intenções, memorandos de entendimento e projetos de cooperação técnica (EMBRAPA, 2009).

No contexto de maior participação internacional da instituição, em 2009 a ARI publicou o Guia de Relações Internacionais da EMBRAPA. No Guia, a EMBRAPA reconhece que é o MRE que prescreve a política de Cooperação Técnica e Científica e que a legislação relacionada a ela estava sendo ampliada nos anos anteriores a publicação (governo Lula). A partir das políticas do MRE, a atuação internacional da instituição se dá com base em consensos formados a partir de discussões internas e aprovados por sua diretoria. As unidades descentralizadas ajudam a coordenar posições. No que diz respeito à cooperação interburocrática, no MRE a EMBRAPA coopera tanto com a Divisão de Ciência e Tecnologia (DCTEC) quanto com a $A B C$, órgão junto do qual promove iniciativas de CID (EMBRAPA, 2009).

Desse modo, a articulação política e o aporte financeiro dependem do MRE (formulação), que, por sua vez, depende das técnicas e pessoal de outras agências como a EMBRAPA para a execução das iniciativas (implementação), como ressaltado anteriormente 
nesse capítulo. Nesse sentido, é "inviável”, compreender a internacionalização das políticas de segurança alimentar do Brasil sem compreender o papel da EMPRAPA (ALBUQUERQUE, 2013).

\section{CONSIDERAÇÕES FINAIS}

O Brasil era, de acordo com Abranches (1988), um "presidencialismo de coalizão" que confere poderes institucionais extensos ao presidente. A união tem a prerrogativa de formular e promover relações internacionais do Brasil. Apesar disso, o MRE cumpre papel de formulador e executor das linhas gerais da PEB. Por outro lado, o processo de pluralização da PEB ganhou força nos governos FHC e Lula, com a abertura de canais de diálogo entre os diversos atores. Esse ambiente tornou-se propício para uma maior cooperação interburocrática. A ampliação de espaços de atuação de outros atores é especialmente destacada na CID. Nesse sentido, segundo Albuquerque (2013), há uma relação entre a internacionalização de políticas públicas e a porosidade decisória do MRE, já que outros atores da burocracia federal atuam na instrumentalização destas políticas.

Já no que diz respeito a organização da ajuda, o Brasil se inseriu no sistema de ajuda como prestador em 1973, com base na sua experiência como receptor e devido à intensificação da ação diplomática na América Latina e na África. Naquele momento, a ABC possuía marco jurídico precário, falta de recursos humanos, financeiros e orçamento próprios, sendo dependente do PNUD. No governo FHC, a ABC foi incorporada diretamente à estrutura do MRE e começou a financiar projetos com orçamento próprio, mas foi no governo Lula que seu orçamento e alcance ganharam grande força ${ }^{10}$. Foi também nesse período que a $A B C$ passou a estar subordinada à Subsecretaria-Geral de Cooperação e Promoção Comercial, uma das áreas do MRE com maior porosidade em relação a outros atores no processo de pluralização da PEB.

\footnotetext{
${ }^{10} \mathrm{~A}$ partir dos dados de execução financeira da $A B C$ para projetos, os valores que foram de cerca de $R \$ 3.300$ milhões em 2002 saltaram para $R \$ 19.300$ milhões em 2009 e $R \$ 37.800$ milhões nos dois últimos anos do governo Lula (2009 e 2010). (Dados disponíveis em abc.gob.br/evolucaofinanceira).
} 
Foi ainda no período de adoção do ProSAVANA na agenda que a CID brasileira teve relevância na PEB. Portanto, a ABC surge como um importante instrumento de projeção. Essa relevância, porém, não refletiu em mudanças institucionais e legais. Constatou-se que há um processo de profissionalização da $A B C$, porém os processos de planejamento, monitoramento e avaliação ainda são fracos.

O processo de CID prestada pelo Brasil inicia-se com as demandas de países em desenvolvimento, que são recebidas pela $A B C$ ou por delegações no exterior. Depois de avaliar as demandas, a Agência chama os órgãos necessários para sua execução/implementação e os termos dos projetos devem, então, ser negociados e aprovados por todos os parceiros. A coordenação do MRE com os demais ministérios tende a ser pacífica e funcional, o que não ocorre sem problemas.

Dentro desse processo, para o ProSAVANA ganha destaque a EMBRAPA, o ator de mais relevante na cooperação agrícola brasileira. Nesse contexto, entre as instituições brasileiras implementadoras, foi a única que apresentou evidências de interesses em expansão na África e em Moçambique, anteriores a 2009.

A partir do exposto, depreende-se que o contexto doméstico brasileiro, analisado por meio dos aspectos elencados por Lancaster, traz informações relevantes para a compreensão da inserção do ProSAVANA na agenda. Entre elas, possibilita observar o papel central da $A B C / M R E$ e da EMBRAPA, embora pareça que a iniciativa tenha sido japonesa em primeiro lugar, como evidenciado pela sequência de fatos que levaram à assinatura do memorando tripartite do programa. Assim, transparecem em relevo os interesses da PEB no período e não tanto interesses privados, como as críticas de Schlessinger (2013), Clements (2015) e outros apontam.

Pelo exposto acerca das instituições e da organização da ajuda, observa-se diversos pontos interessantes. Por exemplo, o crescimento e consolidação de instituições como a $A B C$ e a EMBRAPA parecem ter influenciado e, ao mesmo tempo, ser fruto, do momentum da CID agrícola brasileira. Apesar disso, a falta de coordenação e consolidação dos marcos institucionais e legais da CID foram apontados como problemas que levaram a dificuldades não no nível de agenda, mas na implementação dos projetos. 
Dessa maneira, apesar do processo de horizontalização e pluralização da PEB e, em especial, da CID no Brasil, percebe-se ainda um longo caminho pela frente no que diz respeito ao fortalecimento institucional para um melhor aproveitamento da CID como ferramenta de política externa. Tais desafios apresentam-se ainda maiores no contexto atual, no qual a CID vem perdendo destaque e a própria atuação externa do Brasil vem se transformando, a partir da ascensão da extrema direita. Nesse contexto, a ascensão de Jair Bolsonaro vem acompanhada da crítica da PEB dos governos anteriores, buscando um retorno às relações com o Norte global e tentando desvencilhar suas posições de tudo o que foi realizado nos governos do PT (2003-2016). Portanto, não há no horizonte perspectiva de aprofundamento dos marcos legais e institucionais e da coordenação nessa área.

\section{REFERÊNCIAS}

ABC - AGÊNCIA BRASILEIRA DE COOPERAÇÃO. Gestão Quantitativo Projetos. Disponível em: <http://www.abc.gov.br/Gestao/QuantitativoProjetos> Acesso em 17 de março de 2017.

; JICA - JAPANESE INTERNATIONAL COOPERATION AGENCY. JBPP 10 anos, TCTP 25 anos, [2010]. Disponível em:

<https://www.jica.go.jp/brazil/portuguese/office/publications/pdf/jbpp10a nos.pdf>, Acesso em 15 de maio de 2017.

; MOÇAMBIQUE (MINISTÉRIO DA AGRICULTURA-MINAG). Memorandum de Entendimento sobre a Cooperação Triangular para o Desenvolvimento da Agricultura das Savanas Tropicais em Moçambique. Maputo, Moçambique, 17 de setembro de 2009.

ABRANCHES, Sergio Henrique Hudson de. Presidencialismo de Coalizão: o dilema institucional brasileiro. Dados - Revista de Ciências Sociais, Rio de Janeiro, vol.31, n.1, p.534, 1988.

ALBUQUERQUE, Felipe Leal Ribeiro de. Atores e agendas da política externa brasileira para a África e a instrumentalização da cooperação em segurança alimentar. Dissertação de Mestrado em Relações Internacionais, Universidade do Estado do Rio de Janeiro (UERJ), 2013.

ALMEIDA, Paulo Roberto. Processos decisórios no âmbito da política externa do Brasil.

Revista Porto, n. 02, p. 24-43. 2012. 
ALVES, Ana Cristina. Brazil-Africa Technical Co-Operation - Structure, Achievements and Challenges. South African Institute of International Affairs, Policy Briefing, v.69, p.1-4, 2013.

ANASTASIA, Fátima. MENDONÇA, Christopher. ALMEIDA, Helga. Poder Legislativo e política externa no Brasil: Jogando com as Regras. Contexto Internacional, Rio de Janeiro, v.34, n.2, julho/dezembro 2012, p.617-657.

ARAGÃO, Liduina Gisele Timbo. Ideias interesses e instituições na formação de agendas de políticas públicas: o caso do programa economia solidária. Tese de Doutorado em Política Social, Universidade de Brasília, 2011.

BATISTELLA, M.; E. L. BOLFE. Elos de Cooperação. Revista Paralelos: Corredor de Nacala. v. 1. Embrapa Monitoramento por Satélite, Campinas, São Paulo, 2010.

BÉLAND, Daniel. Ideas, institutions, and policy change. Journal of European Public Policy, n.16, v.5, p.701-718, 2009.

BERTANI, João Pedro Valandro; PAUTASSO, Diego. A Cooperação Brasileira com os Países da África Subsaariana: A Atuação da Agência Brasileira de Cooperação. 3 SEMIC - Seminário de Iniciação Científica ESPM, 2014.

BLYTH, Mark. Structures do not come with an instruction: sheet interests, ideas, and progress in political. Perspectives on Politics, v. 1, n. 4, p. 695-7, 2003.

BRASIL. Constituição da República Federativa do Brasil, 1988. Disponível em:

<http://www.planalto.gov.br/ccivil_03/constituicao/constituicaocompila do.htm>, Acesso em 14 de junho de 2017.

BRASIL. Decreto $n^{\circ}$ 5.979, de 6 de dezembro de 2006. Disponível em:

<http://www.planalto.gov.br/ccivil_03/_ato2004-006/2006/Decreto/D5979.htm\#art6> Acesso em 14 de junho de 2017.

CASON, Jeffrey; POWER, Timothy. Presidentialization, pluralization, and the rollback of Itamaraty: explaining change in Brazilian Foreign Policy making from Cardoso to Lula. International Political Science Review, v. 30, n. 2, p. 117-140, 2009.

CENTER FOR GLOBAL DEVELOPMENT. Carol J. Lancaster. 2021. Disponível em: https://www.cgdev.org/expert/carol-j-lancaster. Acesso em 26 de junho de 2021.

CHICHAVA, Sérgio; DURÁN, Jimena. Civil society organisations' political control over Brazil and Japan's development cooperation in Mozambique: More than a mere whim? LSE Global South Unit Working paper Series, n.2, 2016. 
CLEMENTS, Elizabeth Alice. Brazilian policies and strategies for rural territorial development in Mozambique: South-South cooperation and the case of ProSAVANA and PAA. 2015. Dissertação de mestrado em Geografia, Universidade Estadual Paulista, Presidente Prudente, 2015.

CORTINHAS, Juliano da Silva. Associação de variáveis sistêmicas e domésticas na análise das decisões de política externa. Revista Relações Internacionais no Mundo Atual, n. 6. p. 70101, 2006.

CUNHA, Raphael Coutinho. Preferências Domésticas e Instituições do Processo Decisório em Política Econômica Externa. Revista de Ciências Sociais, Rio de Janeiro, v. 52, n.4, p. 871-910, 2009.

DINIZ, Simone. O Senado Federal e a Deliberação de Atos Internacionais no Presidencialismo Brasileiro. RBCS, v.27, n.80, outubro/2012.

DINIZ, Simone; RIBEIRO, Cláudio. Acordos internacionais e controle parlamentar no Brasil. Revista de Sociologia e Política [online]. 2010, v. 18, n. 37, pp. 75-92. Disponível em: https://doi.org/10.1590/S0104-44782010000300006. Acesso em 26 de junho de 2021.

; _ (2008) The role of the brazilian congress in foreign policy: an empirical contribution to the debate. Brazilian Political Science Review, v.2, n.2, 2008.

DOVAL, Gisele Pereyra. The point of view of the tradition in the institutional identity. The case of the ministry of foreign relations of Brazil. Revista Observare, v.4, n.2 p. 84-103, 2013.

EMBRAPA - EMPRESA BRASILEIRA DE PESQUISA AGROPECUÁRIA. Guia de Relações Internacionais da Embrapa, 2009.

Regimento Interno, 2014. Disponível em:

<https://www.embrapa.br/documents/10180/1546282/RI_SRI.pdf/045f1 b6e-4d8b-49dbb726-aa817a74f0e5>. Acesso em 27 de abril de 2017.

FARIA, Carlos Aurélio Pimenta. Ideias, conhecimento e políticas públicas: Um inventário. Revista Brasileira de Ciências Sociais, v. 18 n. 51, p. 21- 28. 2003.

FARIA, Carlos Aurélio Pimenta; NOGUEIRA, Joana Laura Marinho; LOPES, Dawisson Belém. Coordenação intragovernamental para a implementação da política externa brasileira: o caso do Fórum IBAS. Revista Dados, Rio de Janeiro , v. 55, n. 1, p. 175-220, 2012. 
FIGUEIRA, Ariane C. Roder. Processo decisório em Política Externa no Brasil. Tese de Doutorado em Ciência Política, Faculdade de Filosofia, Letras e Ciências Humanas da Universidade de São Paulo, São Paulo, 2009.

FINGERMANN, Natalia. A Cooperação Trilateral brasileira em Moçambique - Um estudo de caso comparado: o ProALIMENTOS e o ProSAVANA. Tese de Doutorado em Administração Pública e Governo, Fundação Getúlio Vargas, São Paulo, 2014.

FRANÇA, Cássio; SANCHEZ, Michelle Ratton. A horizontalização da política externa brasileira. Valor Econômico, 24 abr. 2009. Disponível em:

<http://www2.senado.leg.br/bdsf/handle/id/449319>, Acesso em 13 de junho de 2017.

GOLDSTEIN, Judith; KEOHANE, Robert O. Ideas and Foreign Policy: Beliefes, institutions and political change. 1 ed. England: Cornell University Press, 1993.

HALL, Peter. Policy Paradigms, Social Learning, and the State: The Case of Economic Policymaking in Britain. Comparative Politics, v. 25, n. 3, p. 275-296, abril, 1993.

. The role of interests, institutions and ideas in the comparative political economy of the industrialized nations. In: LICHBACH, Mark; ZUCHERMAN, Alan (ed.). Comparative politics: rationality, culture and structure. Cambridge: Cambridge University Press, 1997.

HEBLING, Matheus Lucas. Partidos políticos e política externa durante a administração Lula. Teoria e Pesquisa. Revista de Ciência Política. v. 24, n.2, 2015.

HECLO, Hugh. Ideas, Interests, and Institutions. In: DODD, Lawrence; JILSON, Calvin. The Dynamics of American Politics: approaches and interpretation. Westview Press, 1994.

INOCENCIO, Maria Erlan. O Prodecer e as tramas do poder na territorialização do capital no cerrado. Tese de Doutorado em Ciências Humanas, Universidade Federal de Goiás, Goiânia, 2010.

INSTITUTO DE PESQUISA ECONÔMICA APLICADA (IPEA); AGÊNCIA BRASILEIRA DE COOPERAÇÃO $(A B C)$. Cooperação brasileira para o desenvolvimento internacional: 20052009. Brasília: 2010. Disponível em:

<https://www.ipea.gov.br/portal/images/stories/PDFs/Book_Cooperao_Brasileira.pdf>. Acesso em 30 de novembro de 2020.

JICA - JAPANESE INTERNATIONAL COOPERATION AGENCY. JICA em Moçambique, 2016. Disponível em: <https://www.jica.go.jp/mozambique/portuguese/c8h0vm000001jx7patt/brochure_pr_1.pdf> Acesso em 15 de maio de 2017. 
Outline of the Project, 2017. Disponível em:

<https://www.jica.go.jp/project/english/mozambique/002/outline/index.ht ml> Acesso em 15 de maio de 2017.

KAELBERER, Mathias. Ideas, Interests, and Institutions: The Domestic Politics of European Monetary Cooperation. Comparative Politics, v. 35, n.1, 2002.

KEOHANE; Robert Owen; MILNER, Helen V. Internationalization and domestic politics: An introduction. Ed. 1, Cambridge: Cambridge Print-on, 1996.

LANCASTER, Carol. Foreign Aid: Diplomacy, Development, Domestic Politics. Chicago: The University of Chicago Press, 2007

LEITE, lara Costa et al. Brazil's Engagement in International Development Cooperation: The State of the Debate. Rising Powers in International Development. IDS Evidence Report, n.59, maio de 2014.

LIMA, Maria Regina Soares. A política externa brasileira e os desafios da cooperação Sul-Sul. Revista Brasileira de Política Internacional. v.48, n.1, p.24-59, 2005.

LIMONGI, Fernando. A democracia no Brasil: Presidencialismo, coalizão e processo decisório. Revista Novos Estudos - CEBRAP. n.76, p.17-41, 2006.

MACHADO, Ana Paula Cunha. A formulação da política comercial externa agrícola: condicionantes internacionais e domésticos da transformação institucional do Ministério da Agricultura, Pecuária e Abastecimento. Dissertação de Mestrado em Relações Internacionais, Universidade de Brasília, Brasília, 2009.

MILANI, Carlos R. S. Política externa é política pública? Revista Insight Inteligência. Rio de Janeiro, v.18, p.56-75, 2015.

MILNER, Helen Milner. Interests, institutions, and information: domestic politics and international relations. Princeton: Princeton University Press, 1997.

. International Theories of Cooperation Among Nations: Strengths and Weaknesses.

World Politics, n. 44, 1992.

MOÇAMBIQUE (Ministério da Agricultura (MINAG); DPA'S; GETULIO VARGAS FOUNDATION; ORIENTAL CONSULTANTS CO. LTD.; NTC INTERNATIONAL CO. LTD.; TASK CO. LTD. Support Agriculture Development Master Plan in the Nacala Corridor in Mozambique (PROSAVANA-PD). Report No. 2, Mar. 2013. 
MORGENTHAU, Hans. Politics Among Nations: the struggle for power and peace. New York: Knopf. 1962.

PALIER, Bruno; SUREL, Yves. Les "trois I" et l'analyse de l'Etat en action. Revue française de science politique, v. 55, n. 1, fev. 2005.

PINHEIRO, Letícia. Autores y actores de la política exterior brasileña. Disponível em: https://www.passeidireto.com/arquivo/1603309/-leticia-pinheir-autores- y-actores-de-lapolitica-exterior-1. Acesso em 01 de dezembro de 2016.

PROSAVANA. O que é o ProSAVANA, 2015. Disponível em: <

http://www.prosavana.gov.mz/o-que-e-o-prosavana/?lang=pt-pt>. Acesso em 06 de abril de 2016.

PUENTE, Carlos Alfonso Iglesias. A cooperação técnica horizontal brasileira como instrumento da política externa: a evolução da cooperação técnica com países em desenvolvimento - CTPD - no período 1995-2005. Brasília: FUNAG, 2010. Disponível em: <http://funag.gov.br/biblioteca/index.php?route=product/product\&product id=429>. Acesso em 28 de dezembro de 2020.

PUTNAM, Robert D. Diplomacy and Domestic Politics: The Logic of Two-Level Games. International Organization, v. 42, n. 3, p. 427-460, 1988.

SAKAGUCHI, Kato. Japan-Brazil Partnership Program: A framework for triangular cooperation. Scaling Up South-South and Triangular Cooperation. JICA Research Institute, Tóquio, 2012.

SCHLESINGER, Sérgio. Cooperação e investimentos do Brasil na África - O caso do ProSavana em Moçambique. 1a ed, 2013. Disponível em: <http://fase.org.br/wp-

content/uploads/2013/05/Caderno_Prosavana_FASE.pdf>. Acesso em 06 de abril de 2016.

SENATORE, Giuliano Marchini; MATOS, Marcos. Novas fronteiras na África. AgroANALYSIS, São Paulo, v. 32, n. 10, p. 23-24, out. 2012.

SILVA; Elaine; SPÉCIE, Priscila; VITALE, Denise. Atual Arranjo Institucional para a política externa brasileira. Textos para Discussão CEPAL - IPEA, 3. Brasília, DF: CEPAL. Escritório no Brasil/IPEA, 2010.

TAPIA, Jorge R. B.; GOMES, Eduardo R. Ideias, interesses e mudanças institucionais. Tempo Social, v. 20, n. 1, jan. 2008. 